\title{
CORNEAL VASCULARISATION IN CHRONIC DISEASE
}

BY

\author{
P. A. GARDINER, Squadron Leader, R.A.F.V.R.
}

IT has been shown that corneal vascularisation is increased in disease and in trivial illness (Gardiner 1946). The same commúnication analysed a healthy group of people in terms of corneal vascularisation and trivial disease. The aim of the present paper is to analyse the manifestations of corneal vascularisation in a group of ill people and to discuss their significance.

\section{Plan of Procedure}

191 Service patients were examined with the slit-lamp. The following groups of cases were seen :-

\begin{tabular}{lllll} 
Group i. & Proven duodenal ulcers $\ldots$ & $\ldots$ & $\ldots$ & \multicolumn{3}{c}{ Numbers } \\
Group ii. & Rheumatoid arthritis and fibrositis & $\ldots$ & 35 \\
Group iii. & Other gastro-intestinal diseases $\ldots$ & $\ldots$ & 38 \\
Group iv. & $\begin{array}{l}\text { Miscellaneous ; chiefly consisting of } \\
\text { diseases and osteo-arthritis }\end{array}$ & $\ldots$ & $\ldots$ & \\
& diste & &
\end{tabular}

In no case was there a double pathology and in every case the disease was sufficiently severe to warrant either admission to hospital or invaliding from the Service. About $33 \%$ of the total were inpatients and the remainder were examined as they were being. invalided. In view of some of the results it is necessary to enlarge slightly on the types of disease which were seen. The duodenal ulcers were all confirmed radiologically. Group ii consisted of 16 cases of rheumatoid arthritis and 17 cases of fibrositis. Nearly all the latter had had recurrent attacks.

Of the 38 cases in Group iii, 18 had chronic diarrhoea as a predominating symptom and 8 of these could have been functional. The rest of the cases were all organic diseases of the alimentary tract apart from two severe cases of anorexia nervosa. In Group iv the biggest single sub-group was osteo-arthritis in 19 cases. There were 16 chronic skin lesions, 6 of these being eczematous dermatitis. The remaining 10 cases a miscellany of which 4 had chronic pulmonary diseases. The chief common factor in the whole series was the chronic nature of the disease though many individual cases had only had symptoms for a short time. Two control groups of healthy people were examined. 61 of these had had no illness of any kind even of a trivial nature for a mean period of about 12 months (Control 1). 105 had had trivial illnesses during the same 
mean period such as occur in the majority of every population (Control 2). The results are expressed as the mean limbal score of the particular group or characteristic under consideration.

The following additional data were obtained in each case:length of predominating or characteristic symptoms, food habits and ocular symptoms. The corneal vascularity was cprrelated with these findings.

\begin{tabular}{|c|c|c|c|c|c|c|}
\hline Disease- & & & $\begin{array}{l}\text { esults } \\
\text { ABLE I }\end{array}$ & & & \\
\hline \multicolumn{7}{|c|}{ Correlation between disease and corneal vascularity } \\
\hline \multirow{3}{*}{$\begin{array}{l}\text { Number } \ldots \\
\text { Mean Limbal } \\
\text { score } \quad \ldots\end{array}$} & Group i & Group ii & Group iii & Group iv & Control 1 & Control 2 \\
\hline & 75 & 33 & 38 & 45 & 61 & 105 \\
\hline & $7 \cdot 9$ & $8 \cdot 6$ & $7 \cdot 3$ & $6^{\circ} 4$ & $5^{\circ} 9$ & $6 \cdot 6$ \\
\hline
\end{tabular}

Statistically the difference between Groups' $i$ and iv is significant (S.E. \pm 0.68 ; diff. $=1.5$ ) and also between Group ii and iv (S.E. \pm 0.82 ; Diff. $=2 \cdot 2$ ). The highest mean vascularity occurred in the fibro-arthritis group of diseases and in the duodenal ulcers. The least vascularity was in the most healthy group (Control 1) and Group iv was only slightly higher having about the same degree of vascularity as that which was found in Control 2.

\section{Ocular Symptoms- TABLE II}

Correlation of corneal vascularity and ocular symptoms

\begin{tabular}{c|c|c|c|c|c|c} 
& \multicolumn{3}{|c|}{ Symptoms } & \multicolumn{3}{|c}{ No Symptoms } \\
\cline { 2 - 6 } & No. & per cent. & M.L. score & No. & per cent. & M.L. score \\
\hline Control & 24 & 13 & 8.5 & 161 & 87 & 6.0 \\
Ill … & 45 & 24 & 8.3 & 146 & 76 & $7 \cdot 3$ \\
\hline
\end{tabular}

The difference between the proportions complaining of symptoms in the control and the ill groups is significant $\left(\mathrm{chi}^{2}{ }^{2}=7\right.$; and $(\mathrm{P})$ is less than $0^{\circ} 01$ ). In the healthy group the S.E. of the difference between the mean limbal score of those with and without ocular symptoms is $\pm 0 \cdot 85$. This is just a third of the actual difference $(2.5)$ and is therefore significant. In the ill group this difference is not significant.

It is interesting to note that the rheumatic group had a higher percentage with ocular symptoms than any of the others and also 
that the nature of the symptoms was of a different order in the former group (Tables iii and iv).

TABLE III

Correlation between disease and incidence of ocular symptoms

\begin{tabular}{l|c|c|c}
\hline & Examined & With Symptoms & $\begin{array}{c}\text { Per Cent. } \\
\text { With Symptoms }\end{array}$ \\
\cline { 2 - 4 } Group & 75 & 15 & 20 \\
Group ii & 33 & 12 & 36 \\
Group iii & 38 & 11 & 29 \\
Group iv & 45 & 8 & 18 \\
\hline
\end{tabular}

Statistically these results are not significant.

TABLE IV

Correlation between disease and type of ocular symptoms

\begin{tabular}{l|c|c|c|c}
\hline & $\begin{array}{c}\text { Spots in } \\
\text { Visual field }\end{array}$ & Watering & Redness & $\begin{array}{c}\text { Gritty } \\
\text { Sensation }\end{array}$ \\
\cline { 2 - 4 } & & 5 & 3 & \\
Rheumatic & 2 & 5 & 5 & 2 \\
Group ... & 11 & 5 & & \\
\hline
\end{tabular}

There is therefore a higher proportion of subjects in the rheumatic group with watering of the eyes and a much lower proportion with spots in front of the eye. The majority of cases in the other groups were gastro-intestinal.

Food habits:-Each subject was directly asked whether he made a rigid practice of omitting from his diet any of the following:meat, potatoes, green vegetables, milk, eggs, cheese. A dietary deficiency was only noted if it was absolute. (Table V).

The S.E. between the means in each group of deficiency was $\pm 1 \cdot 34$, the observed difference was $3 \cdot 4$. This is therefore considerably more than twice the standard error and therefore significant. The table shows that these people who did not eat meat, potatoes or eggs or any combination of these foods had a significantly higher degree of corneal vascularity than those who did not eat greens, milk or cheese, singly or in combination. Statistically the difference between those who ate a full diet and those who omitted meat, potatoes, and eggs was bordering on significance. 
TABLE V

Correlation of dietary deficiency with corneal vascularity

\begin{tabular}{l|c|c|c}
\hline & \multicolumn{3}{|c}{ Nature of deficiency } \\
\cline { 2 - 4 } & $\begin{array}{c}\text { Meat } \\
\text { Potatoes } \\
\text { Eggs }\end{array}$ & $\begin{array}{c}\text { Greens } \\
\text { Milk } \\
\text { Cheese }\end{array}$ & Full Diet \\
\cline { 2 - 3 } $\begin{array}{l}\text { Number } \ldots \\
\text { Mean Limbal }\end{array}$ & 12 & 22 & 127 \\
Score … & 10.1 & 6.7 & 7.5 \\
\hline
\end{tabular}

Length of symptoms :-Graph I shows the correlation between corneal vascularity and the length of time that symptoms had persisted.

Groups III and IV are shown in a common curve.

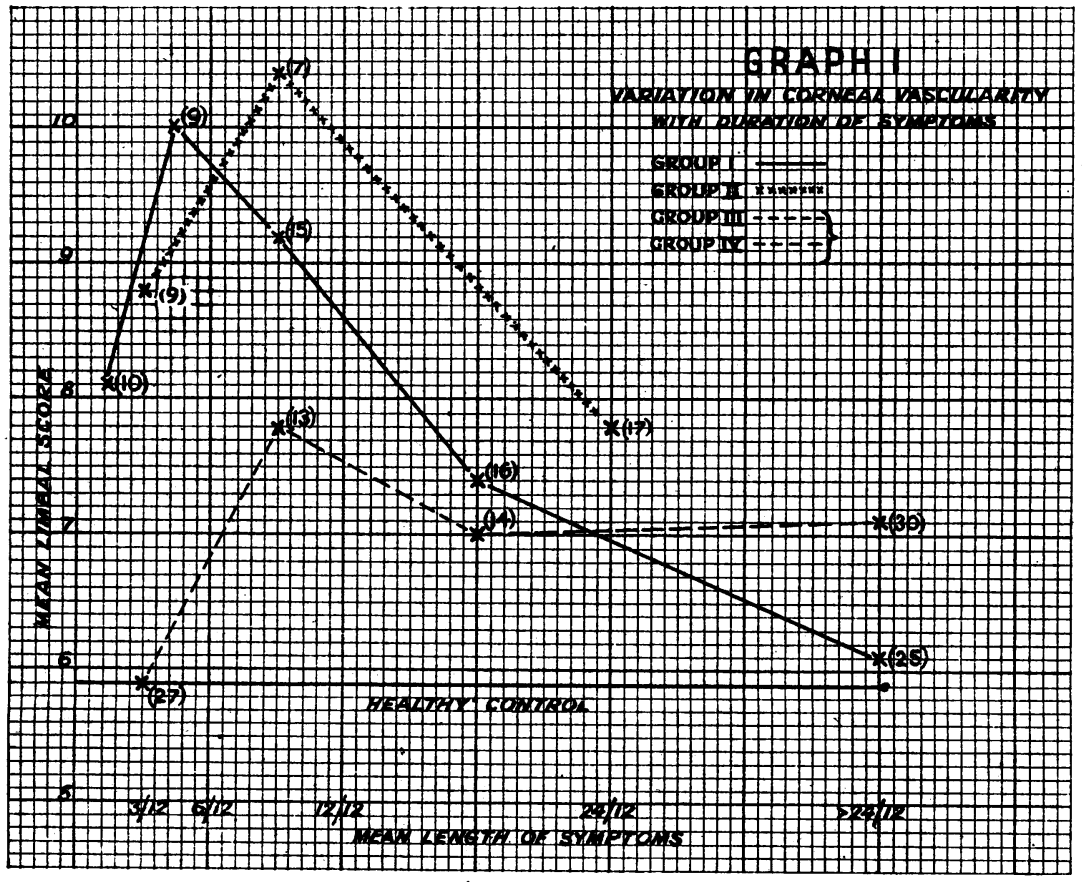

○े

음

흥ํㅇ

앙

흔

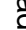

(8)

윽

$\exists$

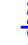

응

字

$$
\text { ชิ }
$$$$
\text { 承 }
$$$$
\text { 익 }
$$

I

N

N

。

స్ట

吕

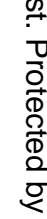


A line has been drawn at the level of vascularity shown by Control 1. All groups show that a peak of vascularity is reached and that its level falls after a certain period but this peak is much higher in Groups I and II and the rise occurs earlier in the disease. In the miscellaneous group the mean vascularity three months after the onset of symptoms is no higher than in the control group.

\section{Discussion}

Increase of vascularity in disease :-In view of the known appearance of corneal vascularisation in deficiency diseases and in states of sub-optimal nutrition, it would be expected that certain chronic diseases would also show increased vascularity of the cornea, especially those more intimately connected with metabolism such as gastro-intestinal disorders. The results shown in Table I justify this expectation strikingly, though not without raising some problems at the same time. There is a notable rise in the limbal score as the groups examined are the positively healthy (Control 1) casual sick (Control 2) suffer from mild chronic disease (Group III and IV) and then from more severe disease such as rheumatoid arthritis and duodenal ulceration (Groups I and II). To some extent at least those results show that the more severe the disease the more vascular the cornea. There are, however, too many exceptions to make this statement dogmatically, particularly if it is applied to the individual case; but over a series it is a fact of significance. The most difficult question arising from Table $I$ is why rheumatoid arthritis and fibrositis which are not obviously metabolic or deficiency diseases, should show a higher degree of vascularity than any other of the diseases, particularly duodenal ulceration, or the other gastrointestinal diseases. Broadly speaking there are two possible explanations of the increased corneal vascularity in rheumatoid arthritis and fibrositis. First, these conditions may be due to or accompanied by vitamin, nutritional, or metabolic disorder of some severity, or secondly, the vascularisation may be a specific process similar to that which occurs in these diseases in other relatively avascular tissues, such as fibrous tissue and synovial membrane.

Although the latter possibility cannot be ruled out the former seems more probable. The vascularisation which occurs in the cornea is not so gross as that which occurs in synovial membrane, nør does it differ in nature from the type of vascularisation known to occur in states of nutritional deficiency. It is unlike the vascularisation which occurs in primary diseases of the cornea. Whether the difterence in symptoms has any bearing on this point, it is difficult to say. The results show that in rheumatoid arthritis and fibrositis, watering, redness and gritty sensations in the eye, seem to occur more frequently than in the other diseases but as will 
be discussed later these symptoms are probably symptoms of excessive vascularisation and as the latter occurs more frequently in this group it is natural to find the symptoms more prominent.

A condition has been recognised for many years, that of goutyarthritic conjunctivitis (Duke-Elder Vol. II) which is a sterile or mucous conjunctivitis occurring in gout and arthritis. The condition found in the subjects under review, however, although often presenting similar symptoms, is occasionally symptomless and usually unassociated with any conjunctivitis. In fact the latter was not noticed once. Possibly an early stage of the conjunctivitis described is what has been found and a specific vascularisation may be associated with it. The whole subject is too big to discuss any more fúlly here and more intensive study will be needed to elucidate the point.

The correlation between the length of symptoms and the degree of vascularity is not easy to explain (Graph 1). An analysis of the subjects who were invalided shows that the majority went out of the Service when symptoms had lasted between six and twelve months. This suggests that few of the more severe cases of incapacity are to be found in the Service with symptoms of longer duration than this, and therefore the falling off in the degree of vascularity shown in all the groups is possibly due to less severe cases coming for examination and not to any real alteration as time goes on. A truly unselected group would have to be examined to establish this point, or alternatively the same cases followed up for two or three years.

Apart from the general higher level of vascularity shown in those suffering from duodenal ulcers and rheumatoid arthritis, it is a marked feature of the graph that these groups show a much more rapid increase in corneal vascularisation than the others. This rapid rise occurring in the first four months of the illness may only be apparent. The results of a previous investigation show that there is a possibility at least that the vascularity may have been raised before symptoms started (Gardiner 1946), in fact that an increase in corneal vascularisation is an early sign of disease. As this phenomenon is not found in the miscellaneous group there may be some underlying significance in the presence or absence of corneal vascularisation in relation to differential diagnoses. There is not sufficient evidence yet to clear up this point.

Aetiology and Symptomatology of corneal vascularisation :- It is only proposed to discuss the aetiology and symptomatology in so far as the present results have any bearing on them. The association with disease has just been dealt with. That corneal vascularisation also depends on nutrition has been abundantly proved (Sydenstricker et al. 1940; Lyle et al. 1944). It has not been possible to correlate the presence of the sign with the absence of any particular article of diet in healthy people and it has been disproved that it is a specific sign of riboflavin deficiency (Lyle et al. 1944). Among the group of 
ill people here examined, however, there is a significant association between the presence of the sign and the absence in the diet of meat, potatoes or eggs singly or in combination. This association is not present when green vegetables, milk or cheese are missing.

This result is in conflict with the evidence collected about healthy people, but it is not incompatible in that under certain conditions of disease not necessarily primarily due to nutritional or vitamin deficiency, there is an abnormal demand for, or a deficient absorption of specific food elements as for example ascorbic acid in wound healing and vitamin $\mathrm{K}$ in obstructive jaundice. If this is agreed it follows that there might be a more definite correlation between corneal vascularisation and the absence of specific nutrients from the diet in disease than in health, without implying that the condition in either state is due to a nutritional deficiency, originally. The result does, however, help to maintain the general position that nutritional causes are operative in the aetiology of corneal vascularisation.

Corneal vascularisation often occurs without symptoms. However, the associations found in the present investigation between ocular symptoms and increased vascularity (Table iii) and the preponderance of symptoms of lacrimation in rheumatoid arthritis (Table v) does suggest that there are definite symptoms which occur. when the condition is very marked. An analysis of the 36 cases with symptoms, seen both in the healthy and ill groups shows that these subjects complaining of watering, redness and grittiness of the eye singly or in combination had the high mean limbal score of $9 \cdot 2$. These symptoms are therefore strongly associated with corneal vascularisation especially when it is borne in mind that there were no cases of frank conjunctivitis. In order not to over stress this it must be noted that 11 with these symptoms out of 191 ill subjects had no excessive vascularisation and one with very marked vascularisation had no symptoms.

Corneal vascularisation as a health index:-Corneal vascularisation is at present used in surveys as an index of the nutritional well being of any group of subjects. It is a useful and accurate sign on which to base comparative estimations. However, the present investigation shows that to draw hard and fast conclusions about nutrition on the basis of altered corneal vascularisation might conceivably be misleading, as this sign also varies in degree in disease. Its use then for nutritional surveys should be confined to healthy people. Moreover it is desirable also to exclude subjects who have had any disease however trivial in the three months before the examination as these may alter the vascularity of the cornea (Gardiner 1946). In practice this exclusion need not be too rigid because a faulty nutrition predisposes to disease and therefore the results probably overlap, but it would be possible to blame nutrition for corneal changes in a 
group of people which in fact might have synchronised with a recent epidemic of some trifling illness. If this is borne in mind the use of this sign could be of considerable value as an index of health in its broadest sense.

The sign may well prove to be of use also in differential diagnosis or prognosis in disease when its significance has been still more clearly defined. Rheumatism, particularly backache for example, is frequently of functional origin. Fibrositis and infective arthritis however, are also commonly associated with this symptom and the differential diagnosis is sometimes difficult. The presence of corneal vascularisation might be indicative of an organic condition though of course not pathognomonic, nor would its absence be a certain index of a functional condition.

\section{Conclusions}

Corneal vascularisation is more frequently present and is of a higher degree in more severe disease than in less severe disease.

Corneal vascularisation is more pronounced in duodenal ulceration and rheumatoid arthritis than in other gastro-intestinal disease, osteo-arthritis and various other diseases.

In disease there is more corneal vascularisation amongst those who complain of ocular symptoms than amongst those with no ocular symptoms.

Lacrimation, grittiness in the eyes and conjunctival congestion accompany corneal vascularisation more often than other symptoms, though vascularisation does occur without any symptoms.

In surveys for comparative health, only healthy subjects should be examined if conclusions are to be drawn about their nutrition.

The presence of corneal vascularisation may prove to be of considerable value in the differential diagnosis of diseases with functional imitations.

\section{Summary}

The variation in corneal vascularity has been examined and discussed in relation to various general diseases, notably duodenal ulceration, rheumatoid arthritis, gastro-intestinal diseases and others.

The local symptoms of corneal vascularisation and its value as an index of health have been discussed. Its possible use in differential diagnosis between functional and organic disease has been indicated.

\section{Acknowledgments}

My thanks are due to Group Captain W. A. S. Duck, O.B.E., Commanding Officer of the R.A.F. Hospital, Northallerton for his permission to carry out this investigation and to the Director 
Gen'eral of the R.A.F. Medical Service for permission to publish the results.

\section{REFERENCES}

DUKE-ELDER.-Text-book of Ophthalmology, Vol. II, Henry Kimpton.

Lyle, T. K., Macrae, T. F. and Gardiner, P. A.-Lancet, Vol. I, p. 393.1944. SYDENSTRICKER, V. P., SEBRELl, W. H., CleckLEY, H. M. and KRUSE, H. D.Jl. Amer. Med. Assoc., Vol. CXIV, p. 2437. 1940.

GARDINER, P. A.-Brit. Jl. of Ophthal., Vol. XXX, p. 225.1946.

\section{IRIDENCLEISIS-A MODIFICATION * \\ BY}

\section{Priestley Smith}

BIRMINGHAM

THREE months ago a woman of 80 came to see me. Both eyes were hard and both lenses opaque. One eye was stone blind, but the other had fairly good projection, and she chose to face cataract surgery on this eye, though realising that the risks were high.

One had, of course, to relieve the glaucoma first; and this meant making a filtering scar that would not be deranged by the subsequent cataract wound. One way would have been to do the glaucoma operation below the cornea; but in that situation it is permanently more exposed to infection. So I decided on iridencleisis above the cornea as usual, but further still from the limbus if possible; and the question arose how to minimise the difficulty of striking the angle of the anterior chamber from so far away.

The procedure which I adopted was as follows. First, I lowered the vitreous pressure by a scleral puncture with a Graefe knife 45 degrees to the temporal side of the vertical meridian and $6 \mathrm{~mm}$. from the limbus. This is my usual first step in glaucoma operations. Next, with a rather narrow parallel-sided kèratome, I made an incision as for an, ordinary preliminary iridectomy, but entering the sclera about $5 \cdot \mathrm{mm}$. above the limbus. With an iris hook I then pulled'a loop of iris into one angle of the wound and snipped off the tip of the prolapse flush with the surface. By stroking the wound from the opposite end I freed one pillar of the loop so that it slipped back into the anterior chamber, leaving the other incarcerated. I do this as a routine in iridencleisis, to reduce the amount of iris tissue left in the wound, one pillar being enough in my experience.

The iris inclusion had now to be prexided with a proper covering of conjunctiva. I made a scissor-cut through the conjunctiva parallel with (and rather longer than) the keratome wound and about $5 \mathrm{~mm}$. above it, and tunnelled under the strip of conjunctiva

\footnotetext{
- Received for publication, June 27, 1946.
} 